\title{
Phonetics in Second Language Acquisition: An Acoustic Study of Fluency in Adult Learners of Spanish
}

\author{
Antônio R.M. Simões \\ University of Kansas
}

\begin{abstract}
A phonetic definition of fluency in natural discourse makes it possible to develop a set of procedures to measure fluency empirically. An analysis of changes in oral communication skills of five American adult learners provides an illustration of how these procedures work. These adults participated in a five-week study abroad program in Spanish. Their overall language proficiency before their departure ranged from Intermediate Low to Advanced, on the ACTFL's OPI scale. Four participants moved to higher intra-major levels, but not to higher inter-major levels. The subjective analysis of the recordings shows that most of these changes are reflected in vocabulary acquisition and more ease in discourse interaction of the four participants. According to the procedures developed in the present analysis, only two participants improved their pronunciation. The results using the present procedures correlate with OPI results.
\end{abstract}

Key words: fluency, phonetics, Second Language Acquisition, SLA, immersion program, adult learning, study abroad, phonology, phonemics, prosody, OPI, ACTFL

\section{Introduction}

There are many ways in which Phonetics and Second Language Acquisition (SLA) can be linked for the benefit of both disciplines. This study seeks to reveal one way in which Phonetics can be useful in studies of SLA. It focuses on the study of fluency, an aspect of pronunciation still vaguely defined in studies of SLA. A person who uses the term "fluent," in reference to oral communication skills of a given person, does it intuitively, and most likely refers to a combination of speaker attributes - the flow of language, intonation and rhythm, speed, accuracy-as Freed (1995) points out. In this study I offer a definition of the term from the point of view of phonetics, which includes most speaking attributes. Based on this definition, I developed and applied an empirical procedure to measure fluency in natural discourse. Through phonetics of discourse I study attributes present in normal discourse-word order, lexicon, semantics, hesitation, filling words, rhythm, stress, vowel quality, pauses, speed, accuracy. The procedure used here does corre- late with results obtained through another tool, the one developed by the American Council on the Teaching of Foreign Language (ACTFL). More importantly, it is objective and reproducible.

In sum, I propose as a measure of fluency the number of accurately pronounced syllable nuclei in sequences of words found acceptable in Spanish discourse. Likewise throughout this investigation, the term "accurate" is to be interpreted from a phonetic point of view. In phonetics, we know that physically all sounds are pronounced within a field of dispersion (Landercy and Renard 1977: 110-11). Figure 1 illustrates this notion of field of dispersion: phonetically, each single vowel has an array of possible realizations. Any speech sound will change according to context, speaker's characteristics, sex, particular mood, regional characteristics and many other factors. Thus, a vowel like [e], as in "mesa," varies physically if the same speaker says "mesa" several times. Furthermore, it is readily apparent that this type of physical variation is infinite when we take into account the other factors just mentioned. The human ear 
learns to perceive all these variations of the same sound as a single sound. Thus, in Linguistics we say that these variations, which correspond to the same sound, are phonetic variations. A phonological or phonemic variation occurs when native speakers perceive different sounds, namely sound differences that will change the meaning of the word. For example, if we say in Spanish "misa" instead of "mesa," we are moving from the field of dispersion of the [e] into the field of dispersion of [i]. Thus, saying "misa" instead if "mesa" is not a simple phonetic variation, but a phonemic variation, since [e] and [i] are two different phonemes. Phonetic variations of [e] in "mesa," for example, include regional changes, changes in the length of [e] because of extra energy or lack of it, changes we observe when a child, a female adult and a male adult pronounce this same vowel, or even when the same person pronounces this word with a cold, or a bad mood, a good mood, and so on. This phonetic variation occurs within the area circled around each vowel, as in Figure 1. Notice that the areas of dispersion overlap. This means that, for instance, an [i] will in some cases be physically similar to an [e], or an [u], due to some of the factors mentioned. These similarities may occur, but context will take care of separating them phonemically. For the purpose of the present research, a given

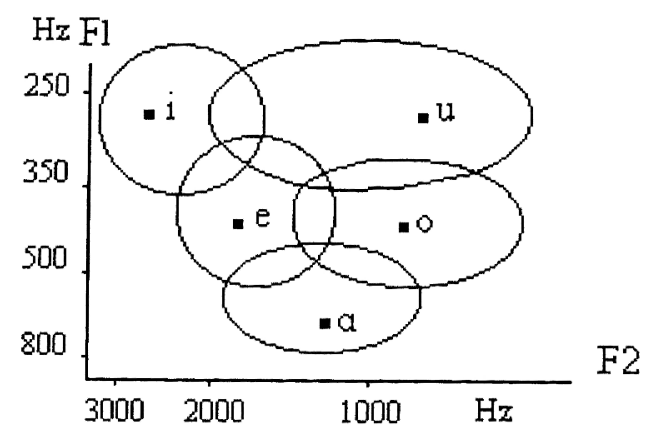

Figure 1

The phonetic manifestation of Spanish vowels is shown in Landercy and Renard (1997: 111), based on Delattre's (1965: 49) description of Spanish vowels. The abbreviation $\mathrm{Hz}$ means Hertz; F1 and F2 mean first and second formants. (Reproduced with permission of Landercy and Renard.) speaker will be accurate if he/she produces his/her vowels within this field of vowel dispersion. It was with these preliminary notions in mind that I undertook this study on changes on fluency.

Studies of changes in oral communication skills of nonnative speakers have attracted ample attention in SLA, from any point of view that we might approach such studies: theoretical, applied or pragmatic. Studies of changes in oral skills among adults can accomplish two immediate purposes. One is to help us to understand the controversy of how age affects language acquisition/learning (Genesee:1976; 1988; Flege 1987). SLA specialists seem to agree, for instance that phonology/phonetics is a domain in which adults are at disadvantage, compared to children (Diller 1978; McLaughlin 1984). Interestingly enough, Swain and Lapkin (1989) studied immersion programs in Canada, and one of their conclusions is that older learners are not disadvantaged, and may in fact learn even faster than younger learners. On the other hand, it is also true that Canadians have a preparation in learning foreign languages that is different from that of Americans. More recently, a series of studies by Wingfield et al $(1989 ; 1992 ; 1994)$ points out that adult learners use prosody to compensate for a possible perceptual loss of segment acquisition. Adults, then, are not at disadvantage, but rather they resort to different strategies to overcome obstacles that they may face in the learning process. These studies may be surprising, especially for those of us who, intuitively, are inclined to think that biologically, the older we are, the less likely we become to learn any component of a second language.

In terms of the practical and pragmatic interest of studies of changes in oral communication skills of nonnative speakers, we see nowadays an increasing number of institutions that send students or employees abroad; in turn these institutions need to know what kind of progress the students or employees make, how to improve such programs, and which factors enhance or prevent learning (Freed 1995). It is hoped that 
Tablo 1: Rating scale for Oral Proficiency Interview, from the Guidelines of the American Council on the Teaching of Foreign Languages. Major levels are in capitals.

\begin{tabular}{|c|c|c|c|c|c|c|c|c|}
\hline \multicolumn{3}{|c|}{ NOVICE } & \multicolumn{3}{|c|}{ INTERMEDIATE } & \multicolumn{2}{|c|}{ ADVANCED } & SUPERIOR \\
\hline Low & Mid & $\mathrm{High}$ & Low & Mid & $\mathrm{High}$ & Adv & Adv High & Superior \\
\hline
\end{tabular}

the present study, and in particular, its procedures, will provide more information which will help to answer theoretical, applied, and pragmatic questions in SLA.

Some of the studies in fluency more closely related to this study are those of Moehle (1984), and Raupach (1984). However, these are studies intended to describe the linguistic surround in which certain elements of fluency appear in the production of oral discourse. Mohele (1984) focused on the analysis of temporal patterns of speech rate, pauses, filled pauses, repetitions, and self-corrections. Similarly, Raupach (1984) attempted to study the correlation between hesitation and formulaic expression. Raupach's (1984) study suggested that German speakers of French improved their fluency by replacing hesitation with formulaic expressions. Other studies that deal with fluency took a different perspective such as perceptual judgment of fluency or sociolinguistics of fluency, to mention but two. Thus, the directions of these studies in adult learning show that it is more than desirable to develop tools for analysis of fluency.

\section{Analysis Protocol}

Five adult learners took part in the Summer Language Institute in Costa Rica for five weeks, during the summer of 1994 . Their ages ranged from around 25 to 55 years. One week before their departure, I interviewed them, using an interview format similar to ACTFL's (1986) Oral Proficiency Interview. Then, one week after they returned, I interviewed them again, using the same interview format. The recordings lasted 19-28 minutes each. Hence, the five participants, were rated according to the rating scale in Table 1 . By using the ACTFL's OPI, it was possible to keep the formats of all interviews the same; the rating scale served to evaluate whether the results using the new tool correlate with ACTFL's rating scale. As the next section will indicate, the results do correlate and add more precision to the analysis of pronunciation.

During the overall rating process, all linguistic domains were monitored, in an attempt to identify domains of special interest. Although the participants showed improvements in most linguistic domains, major improvements were particularly evident in the use of vocabulary, discourse interaction, and pronunciation. After the overall rating, the study concentrated on one aspect of pronunciation in discourse, namely fluency. In addition to the analysis of the recorded interviews, each participant responded in writing to a questionnaire about the program. The questionnaire is a general evaluation form in which students comment upon the organization of the program, its weak and strong points, rapport among all participants, teacher effectiveness, culture shock, primarily extra linguistic factors that may affect their participation and motivation. It is important to have information about extra linguistic factors in this type of linguistic analysis, because such factors provide a more complete picture of student's linguistic experience.

The speech analyzer utilized is CECIL, developed by Owen and Kelso (1993), with a PC386 as its platform, along with regular peripherals of any standard personal computer. The recordings were made with regular good quality audio cassettes and a recorder, in ordinary rooms. The recordings could have been made in an anaechoic chamber, under controlled conditions, as is often done in phonetic laboratories. However, one of the purposes of this investigation is to use samples of spontaneous speech, in a relaxed environment, even if a lot of data is washed out in the process. 


\section{Sampling Procedures}

In order to study fluency, I used a tape recorder counter to make a strictly randomized sampling of speech continua from each interview. The number of speech stretches, i.e. phonetic continua, varied from 25 to 30 per speaker, per interview. For each phonetic continuum of two seconds of speech, segmental syllable nuclei were computed when targeted correctly. Incorrect targeting of segmental syllable nuclei, misuse of the language, and misuse of repeated words were not computed, although they were part of the total duration of speech stretches. The procedures center entirely on vowels. Two samples of transcribed randomized speech continua are shown below with the computation of correct targets, to illustrate these procedures. use of the set of procedures in this investigation requires not only knowledge of phonological patterns of Spanish on the part of the researcher, but also of all other linguistic components. However, the phonetic and phonological components are the most important ones, given that nearly all word groups in Spanish discourse undergo phonological processes such as linking and resyllabification, which need to be correctly interpreted for appropriate counting of syllabic nuclei.

\section{Results and Discussion}

This section summarizes the data and offers an explanation of the findings. The names of the participants are replaced by numbers. As indicated in Table 2, the OPIbased analysis of their language proficiency

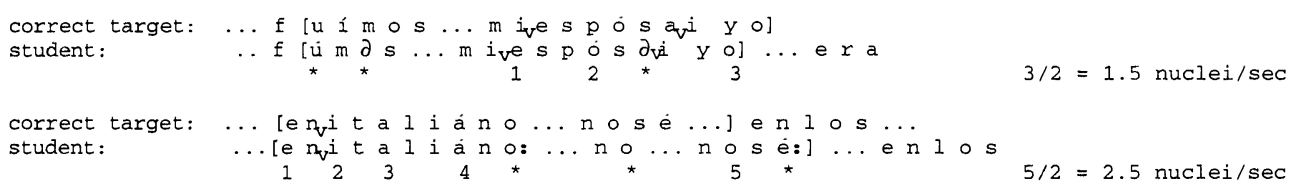

An asterisk indicates a wrong target, whereas whole numbers indicate that syllable nuclei were correctly targeted. Notice that incorrect targets in Spanish are in most cases repeated words, lengthened vowels

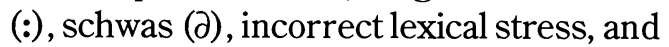
presence of glottal stops. These are not usual features of Spanish. Pauses and hesitations are indicated by dots (...), linking is indicated by $\left({ }_{\mathrm{v}}\right)$, and brackets indicate boundaries of two seconds' duration. The left limit of each speech continuum starts at the amplitude maximum of any first syllable nucleus of a word. This word may be anywhere in a sentence. The right limit will be anywhere that duration reaches two seconds. The right limit may be in the middle of a syllable nucleus, on a consonant, on a pause, anywhere. However, the count of peaks goes to the last full syllable nucleus.

Therefore, interpretation of fluency was done according to the rate of delivery, calculated as the ratio of the number of acceptable syllabic nuclei over the duration of phonetic continua in spontaneous oral discourse. The

showed no change in terms of major language proficiency levels. Although there were no changes from one major level to another, there were changes within the major levels, for participants numbers 1,2, 3 , and 4 . Some of the changes are not presented in Table 2, because these changes alone will not change an overall rate on the ACTFL scale. These are changes in rhythm, intonation, vocabulary expansion, and in extra linguistic factors, especially the building of confidence, an important basis one needs to attain in order to acquire a second language.

In their answers to the questionnaire, all participants, except participant \#5, showed much greater confidence and, consequently, higher motivation as a result of their experience. The confidence they developed let them explore their experience creatively. Correctly or not, these participants tried to construct their own explanation of the grammar of the target language. Finally, their fluency improved as they somehow understood that pauses are less 
Table 2: Evaluation of the five participants in two interviews. The first one took place before the their five-week experience abroad, and the other, upon their return. These evaluation results are based on the Guidelines of the ACTFL Oral Proficiency Interview. The actual names of the students have been replaced by the numbers 1 through 5 .

\begin{tabular}{|l|l|l|}
\hline$\# 1$ & $\begin{array}{l}\text { First Interview } \\
\text { Second Interview }\end{array}$ & $\begin{array}{l}\text { INTERMEDIATE Low } \\
\text { INTERMEDIATE High }\end{array}$ \\
\hline$\# 2$ & $\begin{array}{l}\text { First Interview } \\
\text { Second Interview }\end{array}$ & $\begin{array}{l}\text { INTERMEDIATE High } \\
\text { INTERMEDIATE High, with changes }\end{array}$ \\
\hline$\# 3$ & $\begin{array}{l}\text { First Interview } \\
\text { Second Interview }\end{array}$ & $\begin{array}{l}\text { INTERMEDIATE Mid } \\
\text { INTERMEDIATE High }\end{array}$ \\
\hline$\# 4$ & $\begin{array}{l}\text { First Interview } \\
\text { Second Interview }\end{array}$ & $\begin{array}{l}\text { ADVANCED } \\
\text { ADVANCED High }\end{array}$ \\
\hline$\# 5$ & $\begin{array}{l}\text { First Interview } \\
\text { Second Interview }\end{array}$ & $\begin{array}{l}\text { ADVANCED } \\
\text { ADVANCED, no changes }\end{array}$ \\
\hline
\end{tabular}

frequent in Spanish than in English.

At least three counter arguments may be brought up regarding these improvements. One could say that these subjects are teachers, and that they may have consciously learned about pauses, for instance, before the immersion program. However, even if this were true, they did not apply this knowledge before, either because they could not monitor their use of pauses, or for some other reason. The use of that knowledge came with their experience. A second question that could be raised about the second interview is that these teachers, after the first interview, became more comfortable in front of the tape recorder. Although this is a possibility, I personally do not think that an experienced teacher will show differences on the ACTFL scale from one interview to another by simply overcoming fear of a tape recorder. We either have this personal fear of recorders and the fear will most likely remain in a second interview, or we have a fear which will dissipate after a few minutes in the interview.

The third counter argument, more difficult to discard, is the familiarity with the interview process. Just as knowing what to expect in a language program might have an effect on a learner, being familiar with the interview process may minimize the significance of the changes. However, most participants were already familiar with the OPI format, which weakens this counter argument.

Participant 5 had serious personal difficulties during the entire summer, which may explain why she was the only subject who showed no changes. Interestingly enough, the subjects' judgment of their progress, in the questionnaire, agreed with most of the results of the evaluation done for this study. Some, because they had been interviewed before by ACTFL testers, made a self-evaluation in their responses on the questionnaire. Participant 1 noted: "I feel my speaking ability is getting close to the advanced level (from low [sic] intermediate to high intermediate)." This was also my evaluation before and after the immersion program. On the other hand, participant 3 remarked that her progress was "dramatic." The evaluation in that case went from mid intermediate to high intermediate.

In general, as determined by a linguistic approach to discourse analysis outside ACTFL's OPI domain, the group showed the following discourse characteristics. Syntactically, there were few or no noticeable changes in word order. There were instances of constructions like "^ Me gusta la

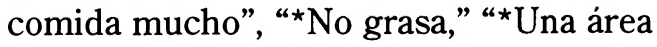
de interés." All of the participants maintained a general SVO pattern in most of their sentences. There were no instances of the common Spanish VSO pattern. In Spanish, underlying SVO very frequently surfaces as VSO. Such patterns used to be explained according to the interplay of theme and rheme (Contreras 1978), but more recently Contreras has taken a different position, which assumes no fixed position for the subject (Contreras 1991).

Some of the interviewees felt more comfortable talking in the present tense in the first interview, and consequently avoided past tenses. In the second interview, these same participants changed this strategy. 
Agreement was a general problem for the group, more serious for some than for others. There was a generally limited use of the pronominal system of Spanish. New lexicon emerged, but there was repeated used of common vocabulary such as "ser," "estar," "querer," "hacer," etc., as well as lack of idiomatic expressions. Intonational and rhythmic patterns which coincide with American English were still present in everyone's speech, stronger for some than for others. I noted a curious trilled pronunciation of the single " $r$ " in Spanish, which indicated a general confusion concerning the pronunciation of the "r." This was observed when the expected single " $r$ " surfaced as a trill: instead of "durante" or "tres," they said "*durrante," "*trres." It is unlikely that the particular pronunciation of the retroflex " $r$ " in Costa Rica, a known phenomenon in Spanish dialectology, created this pronunciation, because it was already noticed in the first interview.

As attested in the preceding sections, the overall approach of the OPI makes it a valuable tool for analysis of overall changes in oral communication skills. It is nonetheless a rating that relies on subjectivity, even though people who use the OPI are very well trained to minimize subjectivity. The advantage of using acoustic phonetics in the analysis of pronunciation is that one can observe linguistic phenomena physically, and make these analyses more objective, open to physical quantification, and relatively more easy to duplicate.

Therefore, I have chosen to use acoustic phonetics as a tool to analyze fluency. The results obtained with the procedures developed for this study are already excellent reflections of what is actually observed by listening carefully to these tapes. Although a well-trained person can have very good judgment of a nonnative pronunciation in spontaneous discourse per se, a precise evaluation of 20-25 minutes of recording that points out changes in a five-week study abroad can become very difficult. It is especially difficult to point out changes in students with higher levels of proficiency in such a short period of training. Eventually it will be necessary to add intonation to these procedures. Although the procedures to evaluate fluency in this study use segmental phonology as a departure, they also include suprasegmental observations such as rhythmic patterns, duration, and lexical stress, by verifying the appropriate realization of vowels in terms of reduction and expansion, pauses, and lexical stress.

Results in Table 3 show one of several statistical tests run for this study. Other tests had the same result, but the MannWhitney test is more appropriate for a relatively small group, as in this study of five participants. In addition, it was more appropriate to use the median, instead of the mean, as the measure of central tendencies, because I am measuring duration, a parameter that can have surprising changes from complete reduction to very long duration in discourse. That is why the Mann-Whitney test is more appropriate than tests which can only use the mean. The table is self-explanatory in the sense that if results are significant this special program will indicate that they are. This program also gives additional information for those who are more familiar with the test and interested in a more detailed reading of the results. Basically, the Mann-Whitney test in this study compares two sets of data: one from the interview before the study abroad program, and the other after the program. This statistical test starts with the assumption that there will be no difference between these two populations, namely between data obtained before and after the program. In other words, the null hypothesis is that there is no difference between the pre- and post-interviews. Therefore, as indicated in Table 3 , only students 1 and 3 showed significant changes in their fluency in Spanish. For students 2, 4, and 5, the null hypothesis cannot be rejected. In other words, although two other students had acquired new lexicon and felt more confident using Spanish, their pronunciation did not improve significantly. Looking at the two students who improved their pronunciation, Student- 1 was at the Intermediate Low, and Student- 3 at Intermediate Mid, before they 
APPLIED LINGUISTICS 93

Table 3: Mann-Whitney Confidence Interval and Test applied to data in Appendix 1. Only students 1 and 3 made significant improvement in their pronunciation of Spanish during their five-week stay in Costa Rica. "INT1 INT2" means "pre and post interviews.

\begin{tabular}{|c|c|c|c|c|c|}
\hline & $\begin{array}{r}\text { Student } 1 \\
\text { INT1 } \quad \text { INT2 } \\
\end{array}$ & $\begin{array}{c}\text { Student } 2 \\
\text { INT1 INT2 } \\
\end{array}$ & $\begin{array}{c}\text { Student } 3 \\
\text { INT1 INT2 } \\
\end{array}$ & $\begin{array}{cc}\text { Student } 4 \\
\text { INT1 } \quad \text { INT2 } \\
\end{array}$ & $\begin{array}{l}\text { Student } 5 \\
\text { Int 1 In } \\
\end{array}$ \\
\hline Number of 2-sec speech samples & 26 & 30 & 25 & 26 & 26 \\
\hline Median & 3.0 & $3.0 \quad 3.5$ & $2.0 \quad 2.5$ & 2.5 & 4.5 \\
\hline $\begin{array}{r}\text { Point estimate for ETA1-ETA2 is } \\
95.0 \text { pct c.1. for ETA1-ETA2 is } \\
\text { West of ETA1=ETA2 vs. ETA1 } 1 . t . \\
\text { ETA2 is significant at } \\
\text { The test is significant at } \\
\text { (adjusted for ties) }\end{array}$ & $\begin{array}{r}-0.5 \\
-1.0,0.0 \\
742.5 \\
0.0329 \\
0.0316\end{array}$ & $\begin{array}{r}0.0 \\
-0.5,0.5 \\
846.5 \\
0.4477 \\
0.4473 \\
\text { Cannot } \\
\text { reject at } \\
\alpha=0.05\end{array}$ & $\begin{array}{r}-0.5 \\
-1.0, \quad 0.0 \\
561.0 \\
0.0477 \\
0.0459\end{array}$ & 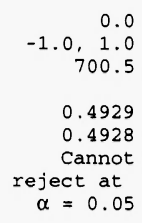 & $\begin{array}{r}-0.0 \\
-0.5, \quad 1.0 \\
723.5 \\
\\
\text { Cannot } \\
\text { reject } \\
\text { since } w> \\
715.0\end{array}$ \\
\hline
\end{tabular}

participated in the program. The three others were Intermediate High and Advanced. Appendix 1 contains all measurements taken for the five students in this study. Their level of departure may be a factor in their significant progress. The size of the group is still limited to render valid any discussion of the age factor, but for the records, Student- 1 is around 25 years old, and student- 3 around 50 years of age.

In sum, these results using the present procedures reflect the results from the OPI rating, even though only two students had significant changes. According to the present procedures, the major changes in pronunciation occurred mostly in vowel quality: less pronunciation of centralized vowels (schwas), less vowel lengthening, more use of linking between words, and finally, due to their confidence in using the language, less use of inappropriate hesitations. Therefore, these changes that are being transferred from English into Spanish constitute part of the language principles that Kiparski (1985) has labeled as post-lexical rules.

\section{Conclusion}

Before undertaking this study I considered the possibility of comparing two different groups, under the same circumstances, as is often done. In other words, the group of adults in this study would ideally be compared with a group of adolescents, for instance. The question that immediately arises in this type of approach is how to actually create comparable circumstances for both groups. Such a task is very difficult if not impossible. How can one imagine adults and adolescents sharing a similar environment in a classroom abroad, so that their learning can be compared? It is highly unlikely that one will find a situation that will permit us to "compare the comparable" as statisticians often say.

Because of the inaccessibility of a situation that will permit a comparison between different age groups, this study has proposed a definition of the term fluency, and a set of procedures that will measure fluency empirically and eventually help in the understanding of the age factor in learning. With such a tool, a number of empirical studies can be accomplished. For instance, native speakers could be measured with this set of procedures, for the purpose of finding fluency average of native speakers. With a native speaker fluency average as a reference one would be able to study how long it would take a non-native to approach or reach a native speaker average fluency. Precise information about the advantages of study abroad programs over regularly-paced curriculum can also be obtained. One way of finding this information is to measure with the tool suggested here how fluent a student becomes after finishing a given semester, and then how fluent a student becomes after an experience abroad. Such comparison tells us more precisely how much time a student usually saves by going abroad. Therefore, the present tool can gather considerable information about learning.

Concerning the results, despite the 
confidence seen in four of the five participants, only two of them improved their pronunciation. It can be noted in passing that the intonation patterns of all of them, as observed through the analysis process, did not seem to have changed. It would certainly be interesting to measure intonational changes as well, but I anticipate no intonational changes. Some of the participants, however, seemed aware of their exaggerated use of high-fall intonation contours, as evidenced in their attempts, in the second interview, to eliminate these characteristics by lowering the volume of their voices, that is, in their reduction alternation of low and high amplitude peaks. However, traces of fundamental frequency of their voices still showed, either as irregular contours at the end of phonetic continua, i.e. speech stretches, or as high-fall contours in declarative final position, where in Spanish there should be low-fall.

From the observations made of these adult participants, language curricula need to include a solid training on pronunciation, especially in skills that eliminate exaggerated use of schwa-like vowels among American students. Although this is an analysis based on the acoustics of speech, one can anticipate that improvement in pronunciation will depend on the appropriate skills for auditory perception of most aspects of pronunciation. Despite the many characteristics of pronunciation, there are always a number of patterns that will recur more often than others in nonnative speakers of Spanish. In the case of the five adult learners, the recurrent inappropriate patterns were: a tendency to vowel centralization, a lack of linking between words, and inappropriate hesitation.

Outside the domain of pronunciation, most speakers in this study showed inconsistencies in their use of gender and number, and unawareness of Spanish VSO patterns (Contreras: 1978; 1991). Of course, there are other curriculum components, of extra linguistic nature, such as administrative organization, and the pedagogical orientation of instructors, that would help students further improve their fluency. In my opinion, however, based on the present acoustic analysis, and borrowing information from a series of studies by Wingfield et al $(1989 ; 1992 ; 1994)$, language curriculum for adults needs to provide a means for the development of strategies that use prosody. Thus, given that adults resort to prosody to compensate for a lack of auditory perception of segments, it is natural to assume that a curriculum for adults needs to provide adequate conditions for the development of this strategy.

\section{WORKS CITED}

American Council on the Teaching of Foreign Languages. 1986. ACTFL Proficiency Guidelines. Hastings-on-Hudson, NY: ACTFL Material Center.

Contreras, Heles. 1978. El orden de las palabras en español. Madrid: Ediciones Cátedra.

Contreras, Heles. 1991. "On the Position of Subjects." Syntax and Semantics, vol 25: Perspectives on Phrase Structure: Heads and Licensing. Ed. Susan D. Rothstein. San Diego: Academic Press, 63-79.

Delattre, Pierre. 1965. Comparing the Phonetic Features of English, French, German, and Spanish. An Interim Report. Heidelberg: Chilton, Groos.

Diller, K.C. 1978. The Language Reading Controversy. Rowley, Mass: Newbury House.

Flege, James. 1987. "A critical period for learning to pronounce foreign languages?" Applied Linguistics 8.2: 162-77

Freed, Barbara F. Personal Communication. 1995. "What Makes Us Think That Students Who Study Abroad Become Fluent?" Second Language Acquisition in a Study Abroad Context. Ed. B.F. Freed. John Benjamins Pub. Co.

Genesee, F. 1976. The role of intelligence in second language learning. Language Learning 26: 267-80

Genesee, F. 1988. Neuropsychology and second language acquisition. Ed. Beebe L. Issues in second language acquisition: multiple perspectives. Cambridge, Mass.: Newbury House, 81-112

Kiparsky, Paul. 1985. "Some Consequences of Lexical Phonology.” Phonology Yearbook 2: 85-138.

McLaughlin B. 1984. Second language acquisition in childhood, 2nd ed. Vol 1: Preschool children. Hillsdale, NJ: Lawrence Erlbaum. 2 vols.

Moehle, M. 1984. A Comparison of the Second Language Speech of Different Native Speakers. Second Language Production. Ed. H. Decher, D. Moehle, M. Raupach. Tubignen: Gunter Narr Verlag.

Landercy, Albert, and Raymond Renard. 1977. Éléments de Phonétique. Bruxelles: Didier, Centre International de Phonétique Appliquée de Mons.

Owen, Edward, and Rich Kelso. 1993. CECIL Reference Manual, version 2.0. Waxhaw, NC: Summer 
Institute of Linguistics.

Raupach, M. 1984. Formulae in Second Language Speech Production. Second Language Production, Ed. H. Decher, D. Moehle, M. Raupach. Tubignen: Gunter Narr Verlag.

Swain, Merryl,and Sharon Lapkin. 1989. "Canadian Immersion and Adult Second Language Teaching: What's the Connection?" Modern Language Jour nal 73.2: 150-59.

Wingfield, Arthur, Andrea H. Alexander, and Sonia Cavigelli. 1994. Does Memory Constraint Utiliza- tion of Top-Down Information in Spoken Word Recognition? Evidence from Normal Aging. Language and Speech, 37.3: 221-35.

Wingfield, Arthur, Cindy J. Lahar, and Elizabeth A.L. Stine. 1989. Age and Decision Strategies in Running Memory for Speech: Effects of Prosody and Linguistic Structure. Psychological Sciences 44,4: 106-13.

Wingfield, Arthur, Sarah C. Wayland, and Elizabeth A.L. Stine. 1992. Psychological Sciences 47.5: 35056.

Appendix 1: Number of syllabic nuclei per second

\begin{tabular}{|c|c|c|c|c|c|c|c|c|c|c|}
\hline $\begin{array}{l}\text { Male \& } \\
\text { Female } \\
\text { speakers } \\
\text { from } \\
\text { C.Rica }\end{array}$ & $\begin{array}{c}\text { Student } \\
1 \\
\text { Intrvw-1 }\end{array}$ & $\begin{array}{c}\text { Student } \\
1 \\
\text { Intrvw-2 }\end{array}$ & $\begin{array}{c}\text { Student } \\
2 \\
\text { Intrvw-1 }\end{array}$ & $\begin{array}{c}\text { Student } \\
2 \\
\text { Intrvw-2 }\end{array}$ & $\begin{array}{c}\text { Student } \\
3 \\
\text { Intrvw-1 }\end{array}$ & $\begin{array}{l}\text { Student } \\
3 \\
\text { Intrvw-2 }\end{array}$ & $\begin{array}{c}\text { Student } \\
\mathbf{4} \\
\text { Intrvw-1 }\end{array}$ & $\begin{array}{c}\text { Student } \\
4 \\
\text { Intrvw-2 }\end{array}$ & $\begin{array}{l}\text { Student } \\
5 \\
\text { Intrvw-1 }\end{array}$ & $\begin{array}{l}\text { Student } \\
5 \\
\text { Intrvw-2 }\end{array}$ \\
\hline 8 & 3 & 2.5 & 3.5 & 2 & 1.5 & 3.5 & 1 & 4 & 5.5 & 5 \\
\hline 5.5 & 2 & 2 & 3 & 3.5 & 2 & 1.5 & 1.5 & 0.5 & 5 & 3.5 \\
\hline 4 & 1.5 & 4 & 1.5 & 3.5 & 3.5 & 2 & 3.5 & 4 & 5 & 6 \\
\hline 7.5 & 0.5 & 3 & 2.5 & 4 & 2.5 & 3 & 5 & 2.5 & 4.5 & 2 \\
\hline 6 & 4.5 & 2 & 3.5 & 3.5 & 2.5 & 3.5 & 2.5 & 1 & 5.5 & 5 \\
\hline 5.5 & 4.5 & 3.5 & 5 & 5.5 & 2 & 1 & 4.5 & 4 & 3.5 & 5.5 \\
\hline 8 & 1.5 & 2 & 4 & 2 & 4.5 & 4 & 1 & 2.5 & 5 & 4 \\
\hline 3.5 & 1 & 3.5 & 4.5 & 4 & 1.5 & 3.5 & 1 & 2.5 & 4 & 2.5 \\
\hline 2 & 3.5 & 3.5 & 2 & 5 & 1.5 & 2.5 & 3.5 & 3 & 5 & 2 \\
\hline 4.5 & 1.5 & 4.5 & 2 & 3 & 2.5 & 4 & 3 & 3.5 & 3.5 & 4 \\
\hline 4 & 4 & 4.5 & 4.5 & 1.5 & 2 & 4 & 4 & 2.5 & 3 & 4 \\
\hline 5.5 & 2.5 & 4.5 & 2.5 & 3 & 2.5 & 4 & 2 & 3 & 4.5 & 3.5 \\
\hline 6 & 4.5 & 3 & 3 & 2.5 & 1.5 & 1 & 4.5 & 4 & 3.5 & 3.5 \\
\hline 8 & 2.5 & 2.5 & 5.5 & 3 & 0.5 & 1.5 & 4 & 0.5 & 7 & 4.5 \\
\hline 5.5 & 4 & 2.5 & 1.5 & 4.5 & 2 & 2 & 1.5 & 1.5 & 3 & 5.5 \\
\hline 6.5 & 2.5 & 3 & 2.5 & 3.5 & 1 & 2 & 1.5 & 3.5 & 2.5 & 5 \\
\hline 6 & 3 & 3.5 & 5 & 3.5 & 1 & 1 & 3.5 & 1.5 & 3.5 & 4 \\
\hline 3.5 & 2 & 2 & 3 & 2.5 & 1 & 1.5 & 2.5 & 2.5 & 5 & 4 \\
\hline 4 & 1.5 & 5 & 5.5 & 2.5 & 2.5 & 3 & 1.5 & 3.5 & 2.5 & 3.5 \\
\hline 6 & 3.5 & 4.5 & 5 & 3.5 & 2.5 & 2.5 & 4.5 & 2.5 & 4.5 & 4.5 \\
\hline 5.5 & 1.5 & 2 & 3.5 & 5.5 & 1.5 & 3 & 1.5 & 2.5 & 5 & 6 \\
\hline 7.5 & 2 & 2 & 2.5 & 2 & 1.5 & 1 & 2.5 & 4 & 3 & 5 \\
\hline 6 & 1 & 3.5 & 3 & 3.5 & $\star$ & 4 & 4 & 1.5 & 4.5 & 3 \\
\hline
\end{tabular}

$\begin{array}{rrrrrrrrrrr}\text { Median } & \text { Median } & \text { Median } & \text { Median } & \text { Median } & \text { Median } & \text { Median } & \text { Median } & \text { Median } & \text { Median } & \text { Median } \\ 5.75 & 2.5 & 3 & 3 & 3.5 & 2 & 2.5 & 2.5 & 2.5 & 4.5 & 4 \\ \text { Mean } & \text { Mean } & \text { Mean } & \text { Mean } & \text { Mean } & \text { Mean } & \text { Mean } & \text { Mean } & \text { Mean } & \text { Mean } & \text { Mean } \\ 5.6964 & 2.5666 & 3.1346 & 3.2833 & 3.3076 & 2.08 & 2.5576 & 2.75 & 2.7592 & 4.1730 & 4.1296\end{array}$

'These results from the fluency of two native speakers from Costa Rica were obtained by the same procedures, and are given simply to have a very preliminary reference. Program particlpants were compared with objective. 